\title{
The Effect of Ta Content on Phase Constitution and Aging Behavior of Ti-Ta Binary Alloys*
}

\author{
Masahiko Ikeda $^{1}$, Shin-ya Komatsu ${ }^{1}$ and Yuichiro Nakamura ${ }^{2}$ \\ ${ }^{1}$ Department of Materials Science and Engineering, Faculty of Engineering, Kansai University, Suita 564-8680, Japan \\ ${ }^{2}$ Graduate Student of Kansai University, Suita 564-8680, Japan
}

Using Ti-Ta alloy to which Ta was added systematically, i.e. Ti-5 mass $\% \mathrm{Ta}, 10 \mathrm{mass} \% \mathrm{Ta}, 20 \mathrm{mass} \% \mathrm{Ta}, 30 \mathrm{mass} \% \mathrm{Ta}, 40 \mathrm{mass} \% \mathrm{Ta}$ and 50 mass $\%$ Ta alloys, the effect of Ta concentration on phase constitution in the solution treated and quenched state and aging behavior is studied by electrical resistivity and Vickers hardness measurements and X-ray diffactometry. All alloys were solution treated at $1173 \mathrm{~K}$ for $3.6 \mathrm{ks}$ and then quenched into ice water (STQ). STQed specimens were isochronally heat treated from 323 to $1173 \mathrm{~K}$. STQed specimens of Ti-50 mass\% Ta alloy were isothermally aging at five different temperatures, $573 \mathrm{~K}, 623 \mathrm{~K}, 673 \mathrm{~K}, 723 \mathrm{~K}$ and $773 \mathrm{~K}$. In the solution treated and quenched state, only reflections of hexagonal martensite, $\alpha^{\prime}$ were obserevd by XRD in Ti-5Ta to 30Ta alloys, whereas only orthorhombic martensite, $\alpha^{\prime \prime}$, was identified by XRD in Ti-40Ta and 50Ta alloys. $\alpha^{\prime \prime}$ in Ti-50Ta alloy is reversely transformed into $\beta$ upon isochronal heat treatment: the starting temperature is situated at a temperature between $623 \mathrm{~K}$ and $673 \mathrm{~K}$. Isothermal aging of this alloy shows that $\alpha^{\prime \prime}$ directly decomposes to $\alpha$ and $\beta$ phases without reverse transformation of $\alpha^{\prime \prime}$ at $573 \mathrm{~K}$ and $623 \mathrm{~K}$ aging. On isothermal aging above $673 \mathrm{~K}, \alpha^{\prime \prime}$ reversely transforms into $\beta$ and then isothermal $\omega$ phase precipitates in the reversed $\beta$.

(Received May 9, 2002; Accepted September 9, 2002)

Keywords: titanium-tantalum alloys, medical applications, orthorhombic martensite, athermal omega, isothermal omega phase, beta phase, electrical resistometry, $X$-ray diffractometry

\section{Introduction}

In some countries of Europe and Asia, especially Japan, the ratio of elders above 65 years old to total population is increasing. ${ }^{1)}$ The major reason for this phenomenon is advance of medical technique and its equipment. For example, equipment for replacement of failed hard tissue, especially medical implants, has been significantly developed and making steady progress. ${ }^{2)}$ Representative of medical implants is artificial bone. ${ }^{3)}$

In generally, artificial bone parts consist with metals, ceramics and polymers. ${ }^{2)}$ The stem of artificial bone, which the part carries the main applied load of the human, is made of metallic materials, i.e. alloys, because alloys have higher strength and toughness than ceramics and polymers. ${ }^{3)}$

A typical metallic material for medical application is stainless steel, especially $\mathrm{Fe}-\mathrm{Cr}-\mathrm{Ni}$ austenitic systems because of excellent corrosion resistance. ${ }^{3)}$ However, nickel is one of a number of strongly toxic metallic elements to the human body. ${ }^{3)}$ Therefore, recently the trend is to reduce the use of $\mathrm{Fe}-\mathrm{Ni}-\mathrm{Cr}$ system stainless steels for the medical applications. ${ }^{3)}$

Many researchers actively investigate $\beta$ Ti alloys ${ }^{4-6)}$ with low elastic modulus for medical implants using $\mathrm{Nb}, \mathrm{Ta}, \mathrm{Zr}$ $\mathrm{Mo}$ and $\mathrm{Fe}$ as alloying elements, e.g. artificial bone. For instance, Ti-35.3Nb-5.1Ta-7.1Zr $\beta$ alloy ${ }^{4)}$ which is the first $\mathrm{Ti}-\mathrm{Nb}-\mathrm{Ta}-\mathrm{Zr}$ alloy developed for medical applications and Ti-13Nb-13Zr near $\beta$ alloy) were produced in the USA. These alloys have low elastic modulus and excellent mechanical properties, i.e. high yield and tensile strength and good fatigue strength in the annealed state. In Japan, Ti-29Nb$13 \mathrm{Ta}-4.6 \mathrm{Zr}$ alloy for medical implants was independently de-

*This Paper was Presented at the Spring Meeting of the Japan Institute of Metals, held in Chiba, on March 30, 2001. veloped by Prof. Niinomi's group in Toyohashi University of Technology. ${ }^{6}$ ) That alloy has a good balance between strength and ductility as well as lower elastic modulus.

There are many reports about $\mathrm{Ti}-\mathrm{Nb}$ binary alloys, e.g. reports about superconductivity ${ }^{7)}$ and shape memory effect of the orthorhombic martensite. ${ }^{8)}$ Ti-Zr binary alloys exhibit complete mutual solubility in the $\alpha$ and $\beta$ phase and $\mathrm{Zr}$ plays the role of a neutral element in titanium. Though alloy in this system are not heat-treatable, there are some reports about that system, e.g. martensite transformation. ${ }^{9)}$

There are some reports of $\mathrm{Ti}-5$ mass $\% \mathrm{Ta}$ alloy as a corrosion resistant alloy ${ }^{10)}$ and Ti-high concentration Ta alloy, e.g. Ti-60 mass $\%$ Ta alloy, for nuclear reactor ${ }^{11)}$ or medical implant application, ${ }^{12)}$ recently. Though Ta is one of the important alloying elements for $\mathrm{Ti}$, as a non-toxic beta stabilizer, ${ }^{3)}$ the Ti-Ta alloy system has not been systematically and actively investigated. Therefore, studies for phase constitution in solution treated and quenched state and aging behavior should be undertaken.

In this study, Ti-Ta alloys to which Ta was added systematically were prepared. Using those alloys, the effect of Ta concentration on phase constitution in the solution treated and quenched state or after aging is investigated by electrical resistivity, Vickers hardness measurements and X-ray diffractometry.

\section{Experimental Procedure}

Ti-5 mass \% Ta, 10 mass $\%$ Ta, 20 mass $\%$ Ta, 30 mass $\%$ Ta, 40 mass $\%$ Ta and 50 mass $\%$ Ta alloys were prepared in a laboratory-scale arc furnace under a high purity argon atmosphere from sponge Ti $(99.8 \%+$ purity) and Ta powder $(99.9 \%)$ as raw materials. Button shaped ingots were hotforged and hot rolled to around $5 \mathrm{~mm}$ thick plates at about $1170 \mathrm{~K}$. Table 1 shows alloy codes and chemical compo- 
Table 1 Alloy code and chemical composition of Ti-Ta alloys used.

\begin{tabular}{ccc}
\hline Alloy code & Ta (mass $\%)$ & O (mass $\%)$ \\
\hline $5 \mathrm{Ta}$ & 5.3 & 0.05 \\
$10 \mathrm{Ta}$ & 10.0 & 0.05 \\
$20 \mathrm{Ta}$ & 19.4 & 0.07 \\
$30 \mathrm{Ta}$ & 29.6 & 0.07 \\
$40 \mathrm{Ta}$ & 39.5 & 0.09 \\
$50 \mathrm{Ta}$ & 49.1 & 0.10 \\
\hline
\end{tabular}

sitions of alloys used. Specimens were prepared from hotrolled plates by cutting, grinding and polishing. After all specimens were encapsulated in quartz tubes under about $3 \mathrm{mPa}$ of atmosphere, the specimens were solution-treated at $1173 \mathrm{~K}$ for $3.6 \mathrm{ks}$ and then quenched into ice water through breaking the quartz tubes (STQ).

STQed specimens for isochronal treatment were isochronally heat-treated for $3.6 \mathrm{ks}$ at temperature intervals of $50 \mathrm{~K}$ up to the solution treatment temperature. The purpose of the isochronal treatment is to estimate the phase transformation temperature during the heating process up to solution treatment temperature. Ti-50Ta alloy was isothermally aged at five different temperatures, i.e. $573 \mathrm{~K}, 623 \mathrm{~K}, 673 \mathrm{~K}, 723 \mathrm{~K}$ and $773 \mathrm{~K}$.

In heat-treated specimens, electrical resistivity was measured at room and liquid nitrogen temperatures ( $\rho_{\mathrm{RT}}$ and $\left.\rho_{\mathrm{LN}}\right)$ and Vickers hardness, using $4.9 \mathrm{~N}$ as applied load, was measured. Phase constitution of all heat-treated specimens was established by X-ray diffraction at room temperature (XRD). Microstructures of STQed specimens were observed by optical microscopy (OM) after mechanical polishing followed by etching with 5 pct $\mathrm{HF}, 25$ pct $\mathrm{HNO}_{3}$ and the balance $\mathrm{H}_{2} \mathrm{O}$.

\section{Results and Discussion}

\subsection{Solution treated state}

Figure 1 shows XRD profiles of STQed Ti-5Ta, 30Ta, 40Ta and 50Ta alloys. Hexagonal martensite, $\alpha^{\prime}$, was identified in Ti-5 and 30Ta alloys quenched from $1173 \mathrm{~K}$. In Ti-40 and 50Ta alloys, orthorhombic martensite, $\alpha^{\prime \prime}$, was identified in STQed state. Optical microstructures of Ti-30Ta, 40Ta and 50Ta alloys quenched from $1173 \mathrm{~K}$ are shown in Fig. 2. Bywater and Christian ${ }^{13)}$ reported orthorhombic martensite was observed above 32 mass\%Ta. Our results of XRD are consistent with their work. The Ti-30Ta alloy exhibited "acicular martensite" with relatively large sized plates. With increase Ta content, the martensite plate size is finer.

Figure 3 shows change in resistivity at room and liquid nitrogen temperatures $\left(\rho_{\mathrm{RT}}\right.$ and $\left.\rho_{\mathrm{LN}}\right)$, resistivity ratio $\left(\rho_{\mathrm{LN}} / \rho_{\mathrm{RT}}\right)$ and Vickers hardness (HV) with increasing Ta content in STQed state. Resisitivity, resistivity ratio and HV monotonously increase with increase in Ta content because of solid solution of Ta. No abrupt change between 30Ta having hexagonal martensite and 40Ta having orthorhombic martensite was observed on those curves. Negative temperature dependence of resistivity was also not apparent in all STQed alloys. Bagariatskii et al. ${ }^{14)}$ reported change in Vickers hardness with Ta content. In that report, hardness is higher than observed in the present results, e.g. $340 \mathrm{HV}$ in $25 \mathrm{Ta}$ alloy. ${ }^{14)}$

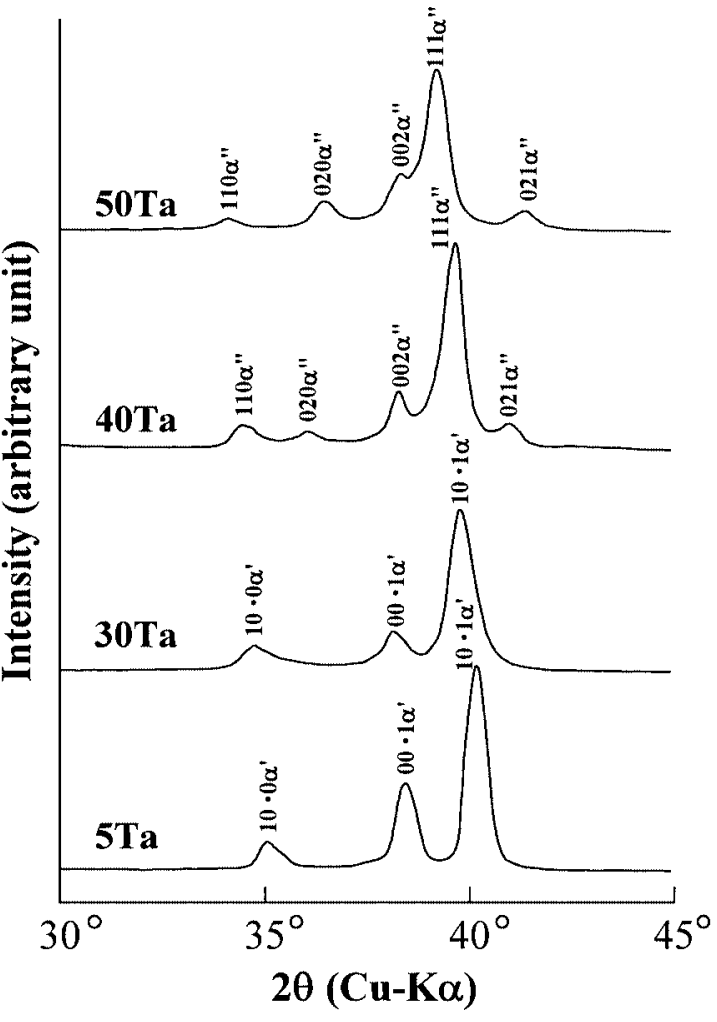

Fig. 1 Examples of X-ray diffraction (XRD) profiles of Ti-5Ta, 30Ta, 40Ta and 50Ta alloys in STQed state.

This higher value is due to a higher content of gas impurities, e.g. oxygen, because their alloys were prepared by powdermetallurgy method. ${ }^{14)}$ Bywater et al. ${ }^{15)}$ also reported, HV values of Ti-22 mass\% Ta, 32 mass\% Ta and 36 mass \% Ta alloys, which were prepared using an argon arc furnace, of about 175 , 178 and 175 in the STQed state, respectively. These HV values are constituent with present HV data, though the increase in $\mathrm{HV}$ with Ta content is not evident because of the narrow composition range between 22 and 36 mass $\%$ Ta which they studied. ${ }^{15)}$

\subsection{Aging behavior}

Figure 4 shows changes in resistivity, resistivity ratio and $\mathrm{HV}$ of Ti-5 to 50 mass\% Ta alloys with an increase in isochronal treatment temperature. Table 2 shows summary of changes in X-ray profiles of Ti-5Ta to 50Ta alloys with increase in isochronal treatment temperature. In Ti-5 to 20 mass \% Ta alloys having hexagonal martensite, no changes in these measurements were observed. When $\alpha$ precipitation occurs during the isochronal treatment in the Ti-5 to 20 mass\% Ta alloys, resistivity decreases and HV increases. However, no change in resistivity and HV were observed, as mentioned above. Therefore, it is considered that the heat treatment time $(3.6 \mathrm{ks})$ is too short for changes of the measurements to appear.

In Ti-30Ta alloy having $\alpha^{\prime}$ martensite, both resistivity and resistivity ratio started to decrease from $723 \mathrm{~K}$ and reached a minimum value at $973 \mathrm{~K}$. Then, the resistivity and its ratio increased with heat-treatment temperature. HV began to increase from $723 \mathrm{~K}$. HV reached maximum at $923 \mathrm{~K}$ and then decrease with increase in the temperature. From XRD results 


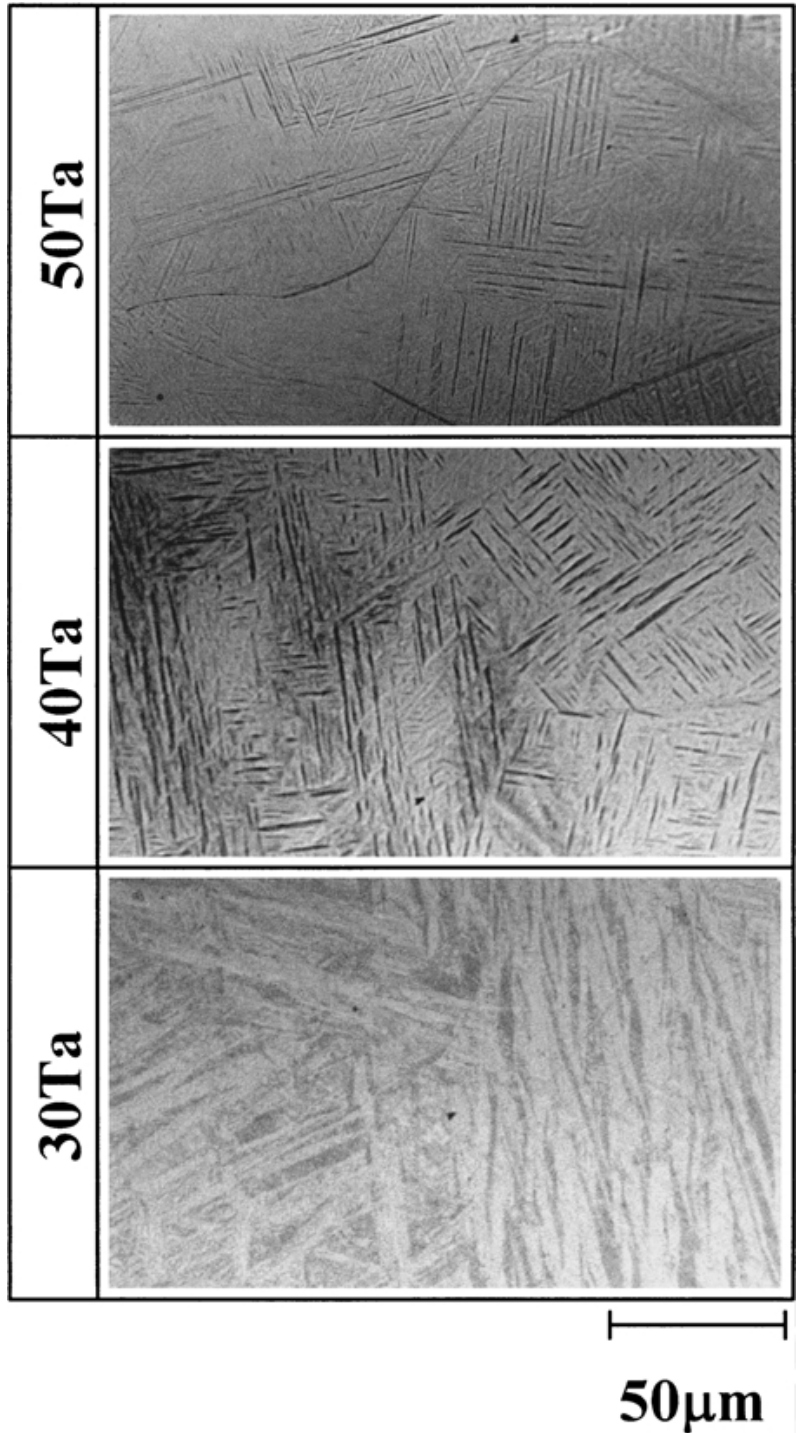

Fig. 2 Optical microstructures of of Ti-30Ta, 40Ta and 50Ta alloys in STQed state.

shown in the Table 2, decomposition of $\alpha^{\prime}$ martensite to $\alpha$ and $\beta$ phase causes decreases of resistivity and resistivity ratio and increase of HV. $\alpha^{\prime \prime}$ martensite was observed in the Ti-30Ta alloy quenched from $973 \mathrm{~K}$ and $1023 \mathrm{~K}$.

In Ti-40 mass\% Ta having orthorhombic martensite, resistivity and resistivity ratio started to decrease from $673 \mathrm{~K}$ and reached a minimum at $873 \mathrm{~K}$. $\mathrm{HV}$ began to increase from $723 \mathrm{~K}$ and reached a maximum at around $823 \mathrm{~K}$ at which minima of $\rho$ and $\rho_{\mathrm{LN}} / \rho_{\mathrm{RT}}$ were observed. From XRD results shown in the Table 2, the change in HV are due to decomposition of $\alpha^{\prime \prime}$ to $\alpha$ and $\beta$ phases.

In Ti-50Ta alloy, resistivity at LN (liquid nitrogen temperature) and resistivity ratio increased at $573 \mathrm{~K}$ and reached a maximum at $673 \mathrm{~K}$. Above $673 \mathrm{~K}$, resistivity at RT and LN and resistivity ratio decreased. Those values became minima at $873 \mathrm{~K}$ and then increased with temperature. HV also began to increase at $573 \mathrm{~K}$ and maximum value was observed at $723 \mathrm{~K}$. Above $723 \mathrm{~K}, \mathrm{HV}$ decreased with increase in temperature. Moreover, values of the decreasing HV curve of $50 \mathrm{Ta}$ are almost the same as those of 40Ta alloy between $823 \mathrm{~K}$ and $973 \mathrm{~K}$. The reason $\rho_{\mathrm{LN}}$ and $\rho_{\mathrm{LN}} / \rho_{\mathrm{RT}}$ increased
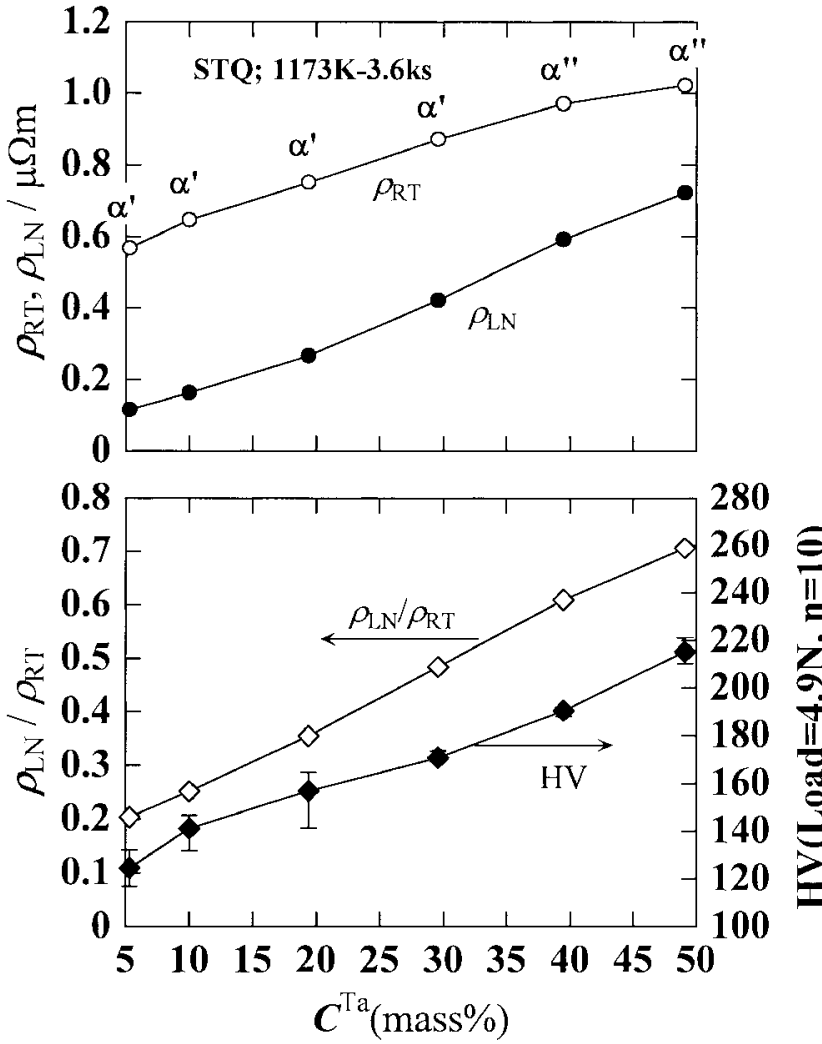

Fig. 3 Changes of electrical resistivity at room and liquid nitrogen temperatures $\left(\rho_{\mathrm{RT}}\right.$ and $\left.\rho_{\mathrm{LN}}\right)$, resistivity ratio $\left(\rho_{\mathrm{LN}} / \rho_{\mathrm{RT}}\right)$ and Vickers hardness (HV, applied load; $4.9 \mathrm{~N}$ ) with increase in Ta content. Phase constitutions identified by XRD were indicated near plots of $\rho_{\mathrm{RT}}$.

Table 2 Summary of phase constitutions of all isochronally heat-treated Ti-Ta alloys by XRD at RT, except for Ti-50Ta alloy heat treated at $323 \mathrm{~K}$ for $3.6 \mathrm{ks}$.

\begin{tabular}{rcccccc}
\hline & $5 \mathrm{Ta}$ & $10 \mathrm{Ta}$ & $20 \mathrm{Ta}$ & $30 \mathrm{Ta}$ & $40 \mathrm{Ta}$ & $50 \mathrm{Ta}$ \\
\hline STQ & $\alpha^{\prime}$ & $\alpha^{\prime}$ & $\alpha^{\prime}$ & $\alpha^{\prime}$ & $\alpha^{\prime \prime}$ & $\alpha^{\prime \prime}$ \\
$323 \mathrm{~K}$ & $\alpha^{\prime}$ & $\alpha^{\prime}$ & $\alpha^{\prime}$ & $\alpha^{\prime}$ & $\alpha^{\prime \prime}$ & - \\
$373 \mathrm{~K}$ & $\alpha^{\prime}$ & $\alpha^{\prime}$ & $\alpha^{\prime}$ & $\alpha^{\prime}$ & $\alpha^{\prime \prime}$ & $\alpha^{\prime \prime}$ \\
$473 \mathrm{~K}$ & $\alpha^{\prime}$ & $\alpha^{\prime}$ & $\alpha^{\prime}$ & $\alpha^{\prime}$ & $\alpha^{\prime \prime}$ & $\alpha^{\prime \prime}$ \\
$573 \mathrm{~K}$ & $\alpha^{\prime}$ & $\alpha^{\prime}$ & $\alpha^{\prime}$ & $\alpha^{\prime}$ & $\alpha^{\prime \prime}$ & $\alpha^{\prime \prime}$ \\
$623 \mathrm{~K}$ & $\alpha^{\prime}$ & $\alpha^{\prime}$ & $\alpha^{\prime}$ & $\alpha^{\prime}$ & $\alpha^{\prime \prime}$ & $\alpha^{\prime \prime}$ \\
$673 \mathrm{~K}$ & $\alpha^{\prime}$ & $\alpha^{\prime}$ & $\alpha^{\prime}$ & $\alpha^{\prime}$ & $\alpha^{\prime \prime}$ & $\alpha^{\prime \prime}+\beta$ \\
$723 \mathrm{~K}$ & $\alpha^{\prime}$ & $\alpha^{\prime}$ & $\alpha^{\prime}$ & $\alpha^{\prime}$ & $\alpha+\beta$ & $\beta+\omega$ \\
$773 \mathrm{~K}$ & $\alpha^{\prime}$ & $\alpha^{\prime}$ & $\alpha^{\prime}$ & $\alpha+\beta$ & $\alpha+\beta$ & $\beta+\omega$ \\
$823 \mathrm{~K}$ & $\alpha^{\prime}$ & $\alpha^{\prime}$ & $\alpha^{\prime}$ & $\alpha+\beta$ & $\alpha+\beta$ & $\alpha+\beta$ \\
$873 \mathrm{~K}$ & $\alpha^{\prime}$ & $\alpha^{\prime}$ & $\alpha^{\prime}$ & $\alpha+\beta$ & $\alpha+\beta$ & $\alpha+\beta$ \\
$923 \mathrm{~K}$ & $\alpha^{\prime}$ & $\alpha^{\prime}$ & $\alpha^{\prime}$ & $\alpha+\beta$ & $\alpha^{\prime \prime}+\beta$ & $\alpha^{\prime \prime}$ \\
$973 \mathrm{~K}$ & $\alpha^{\prime}$ & $\alpha^{\prime}$ & $\alpha^{\prime}$ & $\alpha^{\prime \prime}+\alpha^{\prime}$ & $\alpha^{\prime \prime}+\beta$ & $\alpha^{\prime \prime}$ \\
$1023 \mathrm{~K}$ & $\alpha^{\prime}$ & $\alpha^{\prime}$ & $\alpha^{\prime}$ & $\alpha^{\prime \prime}+\alpha^{\prime}$ & $\alpha^{\prime \prime}$ & $\alpha^{\prime \prime}$ \\
$1073 \mathrm{~K}$ & $\alpha^{\prime}$ & $\alpha^{\prime}$ & $\alpha^{\prime}$ & $\alpha^{\prime}$ & $\alpha^{\prime \prime}$ & $\alpha^{\prime \prime}$ \\
$1123 \mathrm{~K}$ & $\alpha^{\prime}$ & $\alpha^{\prime}$ & $\alpha^{\prime}$ & $\alpha^{\prime}$ & $\alpha^{\prime \prime}$ & $\alpha^{\prime \prime}$ \\
$1173 \mathrm{~K}$ & $\alpha^{\prime}$ & $\alpha^{\prime}$ & $\alpha^{\prime}$ & $\alpha^{\prime}$ & $\alpha^{\prime \prime}$ & $\alpha^{\prime \prime}$ \\
\hline
\end{tabular}

from $573 \mathrm{~K}$ is the reverse transformation of $\alpha^{\prime \prime}$ to metastable $\beta$ phase shown in XRD results (Fig. 5). Maximum value of $\mathrm{HV}$, about $400 \mathrm{HV}$, is higher than those of Ti-30Ta and 40Ta alloys. The extremely high $\mathrm{HV}$ is due to isothermal $\omega$ precipitation in Ti-50Ta alloy heat-treated up to $723 \mathrm{~K}$, as shown in Fig. 5.

In $\mathrm{Ti}-35$ mass $\% \mathrm{Nb}$ alloy having $\alpha^{\prime \prime}$, it is already reported 

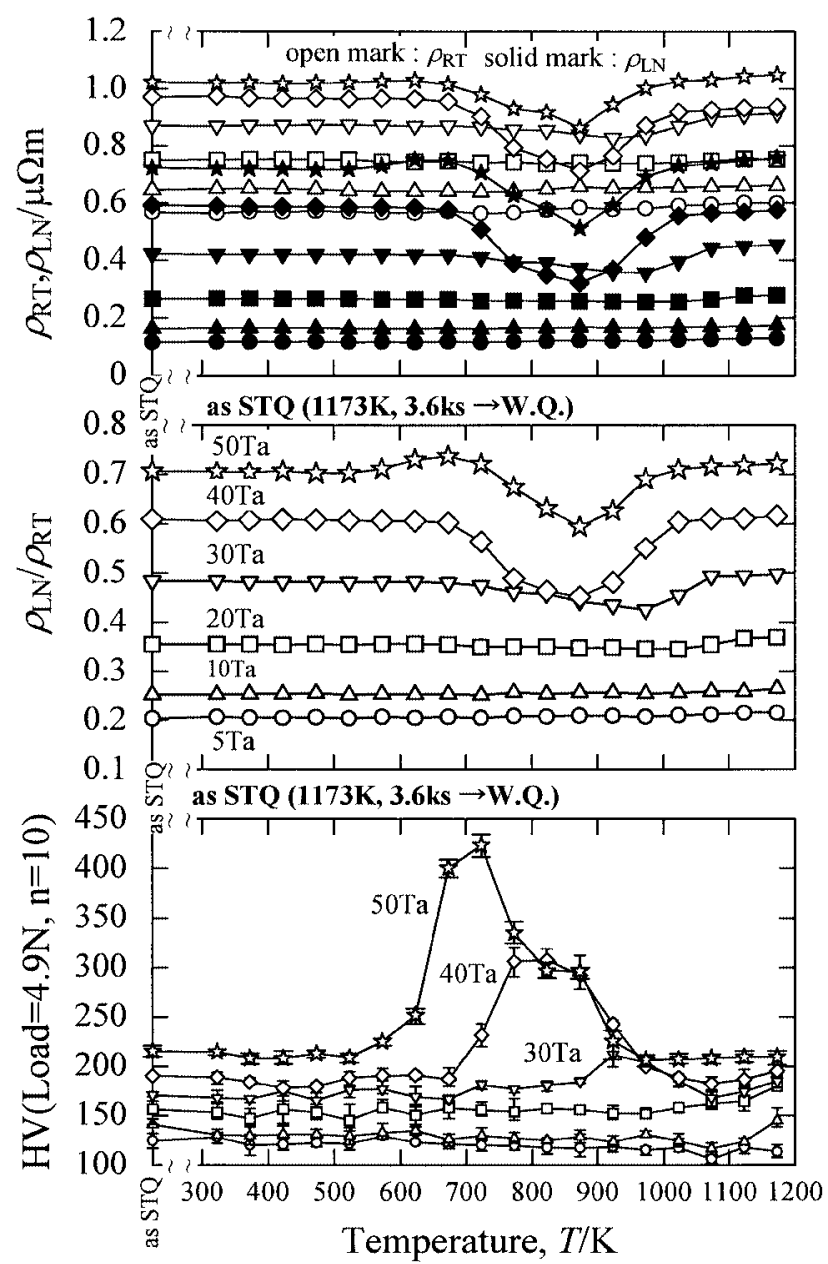

Fig. 4 Changes in $\rho_{\mathrm{RT}}, \rho_{\mathrm{LN}}, \rho_{\mathrm{LN}} / \rho_{\mathrm{RT}}$ and $\mathrm{HV}$ with increase in heat treatment temperature. In this study, isochronal heat treatment means isothermal heat treatment at intervals of $50 \mathrm{~K}$ up to $1173 \mathrm{~K}$ for $3.6 \mathrm{ks}$.

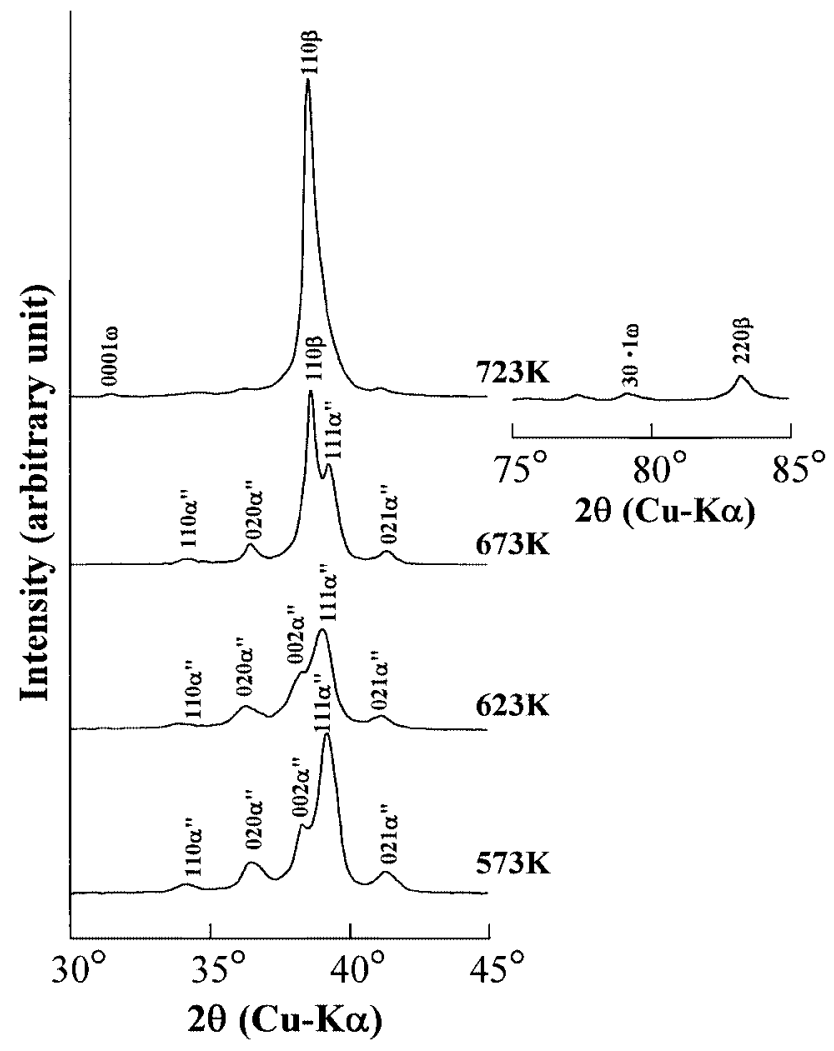

Fig. 5 Example of change in XRD profile of Ti-50Ta alloy with isochronal heat treatment. that $\rho_{\mathrm{LN}}$ and resistivity ratio increased by reverse transformation from $\alpha^{\prime \prime}$ into $\beta{ }^{16)}$ The reason why the increment of $\rho_{\mathrm{LN}}$ is larger than that of $\rho_{\mathrm{RT}}$, i.e. resistivity ratio increases by reverse transformation, is that reversely transformed metastable $\beta$ phase has a negative temperature dependence of electrical resistivity. ${ }^{16)}$ It is expected that the starting temperature for reverse transformation of $\mathrm{Ti}-50 \mathrm{Ta}$ alloy will be located at a temperature between $623 \mathrm{~K}$ and $673 \mathrm{~K}$.

Ti-50Ta alloy in which reverse transformation occurred was isothermally aged at five different temperatures within range between $573 \mathrm{~K}$ and $773 \mathrm{~K}$. Figure 6 shows changes in $\rho_{\mathrm{RT}}, \rho_{\mathrm{LN}}, \rho_{\mathrm{LN}} / \rho_{\mathrm{RT}}$ and Vickers hardness (HV) of Ti-50Ta alloy with aging time at various aging temperatures. Resistivity at $\mathrm{LN}$ and resistivity ratio started to increase from $30 \mathrm{ks}$ on $573 \mathrm{~K}$ aging and $12 \mathrm{ks}$ on $623 \mathrm{~K}$ aging, respectively. HV began to increase from $60 \mathrm{ks}$ on $573 \mathrm{~K}$ aging and $12 \mathrm{ks}$ on $623 \mathrm{~K}$ aging, respectively. Incubation period of HV was observed, e.g. up to $30 \mathrm{ks}$ on $573 \mathrm{~K}$ aging. Only orthorhombic martensite, $\alpha^{\prime \prime}$ was identified in Ti-50Ta alloy aged for times within the incubation period. At longer times, at which resistivity started to increase, e.g. $120 \mathrm{ks}$ on $573 \mathrm{~K}$ aging, beta phase was identified by XRD as shown in Figs. 7 and 8, respectively.

R. Davis, H. M. Flower and D. R. F. West reported that decomposition of $\alpha^{\prime \prime}$ martensite into Mo enriched $\alpha^{\prime \prime}$ and Mo denuded $\alpha^{\prime \prime}$ in Ti-8 mass $\%$ Mo alloy during aging at $723 \mathrm{~K}^{17)}$ and they also reported that the similar decomposition of $\alpha^{\prime \prime}$ in

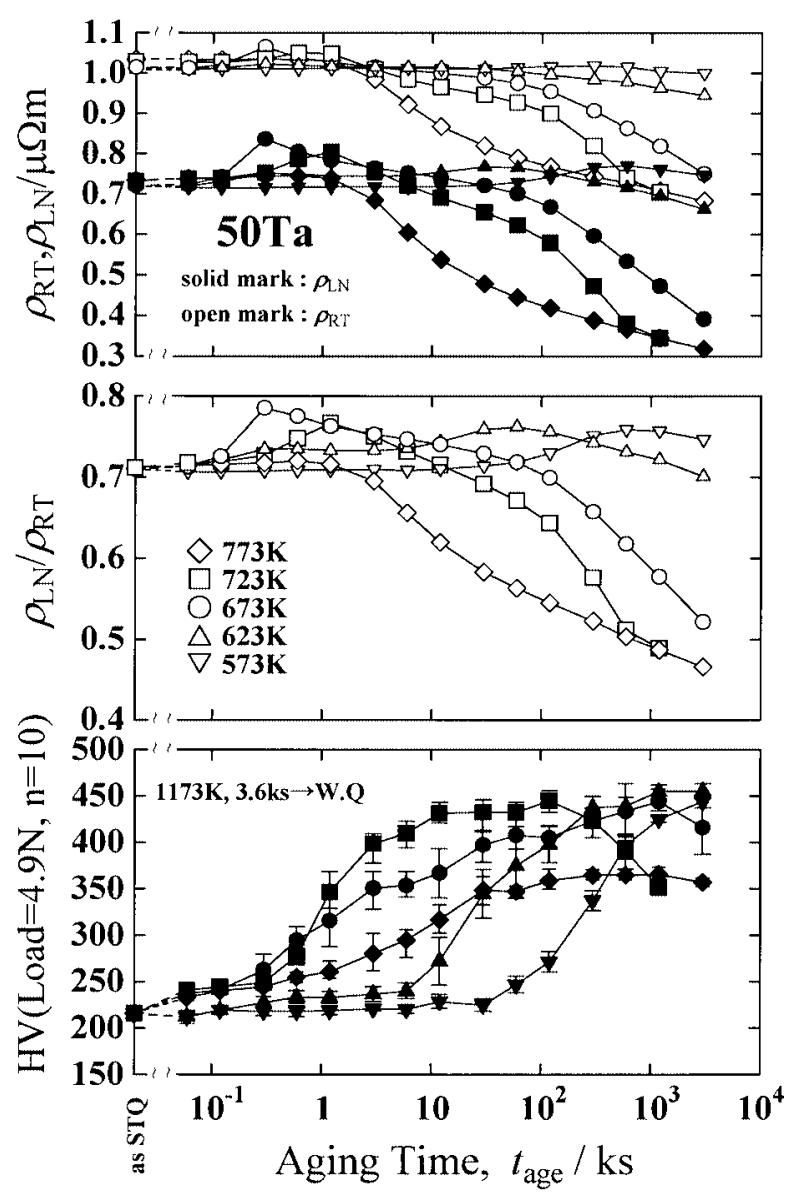

Fig. 6 Changes in $\rho_{\mathrm{RT}}, \rho_{\mathrm{LN}}, \rho_{\mathrm{LN}} / \rho_{\mathrm{RT}}$ and $\mathrm{HV}$ of Ti-50Ta alloy with isothermal aging at five different temperatures, $573 \mathrm{~K}, 623 \mathrm{~K}, 673 \mathrm{~K}, 723 \mathrm{~K}$ and $773 \mathrm{~K}$. 


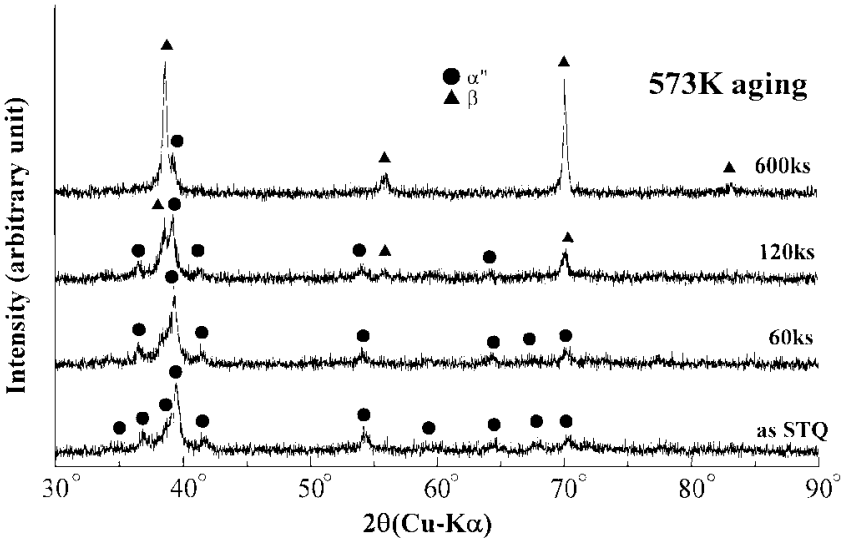

Fig. 7 Example of change in XRD profile of Ti-50Ta alloy with isothermal aging at $573 \mathrm{~K}$

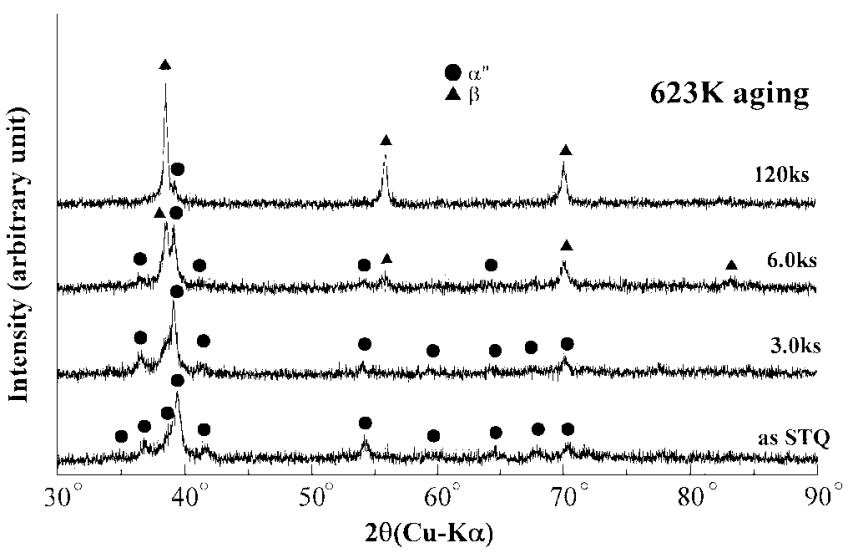

Fig. 8 Example of change in XRD profile of Ti-50Ta alloy with isothermal aging at $623 \mathrm{~K}$.

Ti-Nb alloys was observed. ${ }^{18)}$ Therefore, though alloying element between their works ${ }^{17,18)}$ and present work is different, as aging proceeds at $573 \mathrm{~K}$ and $623 \mathrm{~K}$, it is considered that $\alpha^{\prime \prime}$ decomposes into Ta enriched $\alpha^{\prime \prime}$ and Ta denuded $\alpha^{\prime \prime}$ and then Ta enriched $\alpha^{\prime \prime}$ reversely transforms into $\beta$ phase at the aging temperature. Furthermore, by quenching for measurements of resistivity, $\mathrm{HV}$ and XRD, it is also considered that the reversely transformed $\beta$ phase retained to room temperature. However, no reflection of isothermal $\omega$ phase was identified in the specimen aged at further aging time, i.e. $600 \mathrm{ks}$ on $573 \mathrm{~K}$ aging and $120 \mathrm{ks}$ on $623 \mathrm{~K}$ aging.

On aging at $673 \mathrm{~K}$, resistivity at $\mathrm{LN}$ and resistivity ratio abruptly increased at $0.3 \mathrm{ks}$ and then increased further with aging. HV increased from $0.3 \mathrm{ks}$ when the abrupt increase of $\rho_{\mathrm{LN}}$ and $\rho_{\mathrm{LN}} / \rho_{\mathrm{RT}}$ appeared. Maximum HV was at $120 \mathrm{ks}$ and then decreased with aging time. Figure 9 shows the change of $\mathrm{X}$-ray diffraction profiles with increase in aging time. Reflections of $\beta$ phase were identified at $0.3 \mathrm{ks}$ and intensity of those reflections became stronger with aging time. Reflections of isothermal $\omega$ phase were first identified at $600 \mathrm{ks}$. However, that intensity is very weak.

H. M. Flower, R. Davis and D. R. F. West reported that from results of aging behavior of Ti-20 mass $\% \mathrm{Nb}$ alloy on $673 \mathrm{~K}$ aging, complex structure could be produced when reversion of $\alpha^{\prime \prime}$ into $\beta$ and precipitation occurred on aging and partial transformation to martensite took place on cooling. ${ }^{18)}$ Therefore, though alloying element between their work ${ }^{18)}$ and

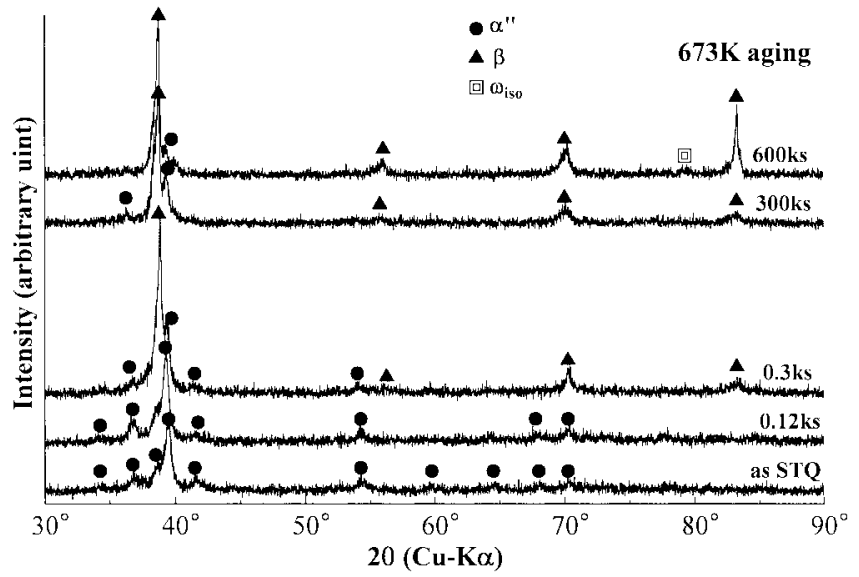

Fig. 9 Example of change in XRD profile of Ti-50Ta alloy with isothermal aging at $673 \mathrm{~K}$.

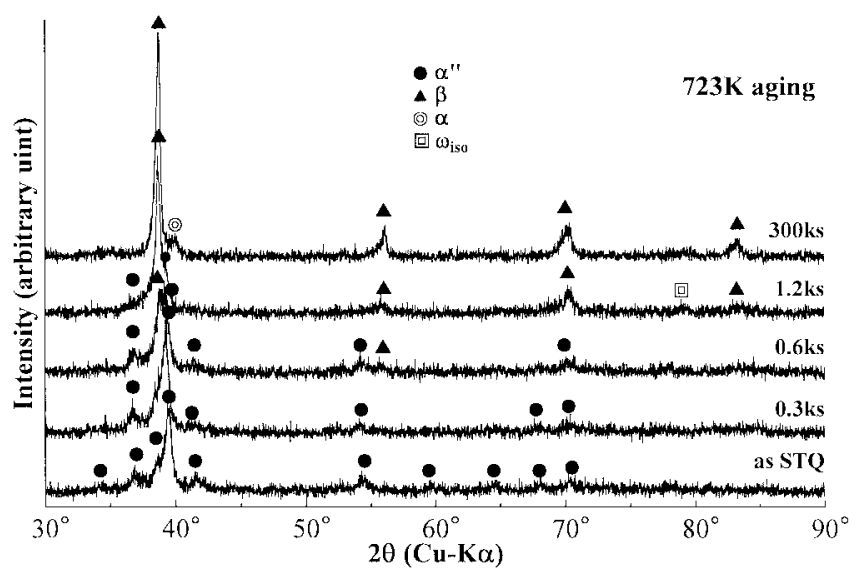

Fig. 10 Example of change in XRD profile of Ti-50Ta alloy with isothermal aging at $723 \mathrm{~K}$.

present work is different, it is considered that on aging at $673 \mathrm{~K} \alpha^{\prime \prime}$ reversely transformed into $\beta$ at $673 \mathrm{~K}$ and then $\beta$ decomposed to Ta enriched $\beta$ and denuded Ta $\beta$ phase during aging at $673 \mathrm{~K}$ for $0.3 \mathrm{ks}$. After aging for $0.3 \mathrm{ks}$, denuded $\beta$ re-transformed into $\alpha^{\prime \prime}$ while enriched $\beta$ phase is retained to room temperature during quenching into ice water. Ta concentration difference between the enriched $\beta$ and denuded $\beta$ will be small because of short time aging, i.e. only $0.3 \mathrm{ks}$ ( 5 min). Therefore, Ta enriched $\beta$ phase is a metastable state, because resistivity at $\mathrm{LN}$ is larger than that at $\mathrm{RT}$, i.e. volume fraction of athermal $\omega$ increases with decrease in temperature. ${ }^{19)}$ When stability of $\beta$ phase increases, volume fraction of formed athermal $\omega$ decreases with decrease in temperature, i.e. temperature dependence of resistivity changes from negative to positive. ${ }^{19)}$ On further the aging, denuded $\beta$ phase transforms into isothermal $\omega$ phase and finally $\alpha$ phase, while enriched $\beta$ phase becomes stable $\beta$ phase.

On aging at $723 \mathrm{~K}$, resistivity at $\mathrm{LN}$ and resistivity ratio increased from $0.3 \mathrm{ks}$ and the resistivity and resistivity ratio peaked at $1.2 \mathrm{ks}$. $\rho_{\mathrm{LN}}$ and the ratio then decreased with aging at $723 \mathrm{~K}$. HV significantly increased from $0.6 \mathrm{ks}$ and maximum $\mathrm{HV}$ was achieved at around $120 \mathrm{ks}$. Figure 10 shows examples of X-ray diffraction profiles of specimens aged for suitable aging times. Reflections of $\beta$ phase were identified at $0.6 \mathrm{ks}$. Reflections of isothermal $\omega$ phase were 


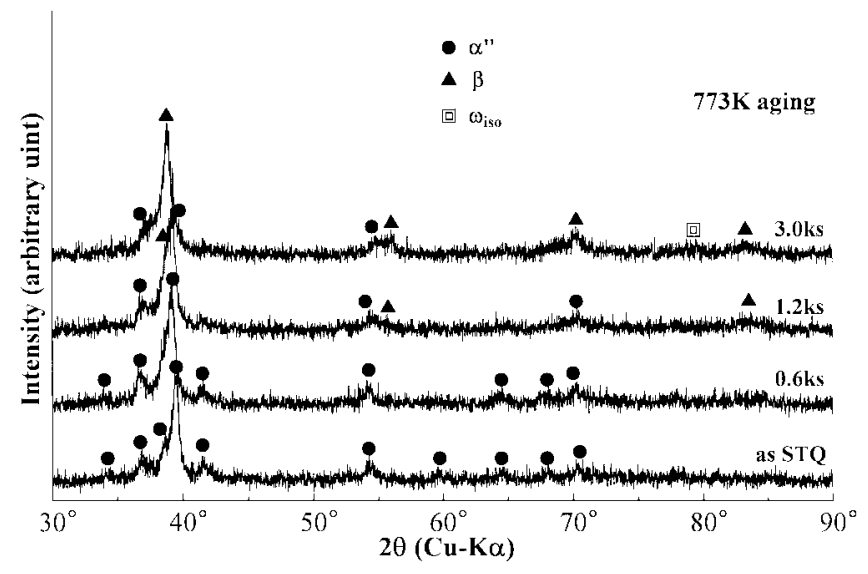

Fig. 11 Example of change in XRD profile of Ti-50Ta alloy with isothermal aging at $773 \mathrm{~K}$.

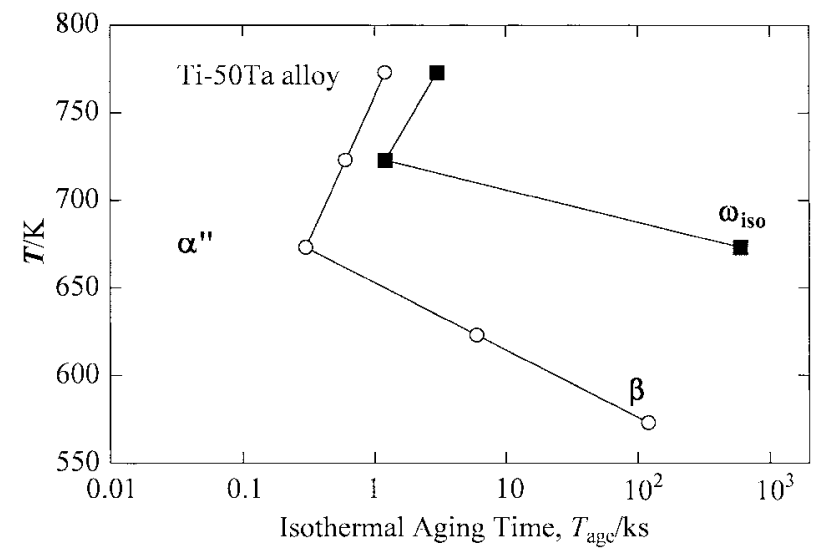

Fig. 12 Isothermal transformation diagram of Ti-50Ta alloy. Open circle marks, $\bigcirc$ indicate aging time at which $\beta$ phase was first identified by XRD. Solid circle marks, also indicate aging time at which isothermal $\omega$ phase was first identified by XRD.

first identified at $1.2 \mathrm{ks}$. At $300 \mathrm{ks}, \alpha$ phase appeared in Xray diffraction profile. On aging at $773 \mathrm{~K}$, resistivity at $\mathrm{LN}$ and resistivity ratio slightly increased to $0.6 \mathrm{ks}$ aging and then decreased with increase in aging time. HV significantly increased from $0.6 \mathrm{ks}$ and maximum value of $\mathrm{HV}$ reached at around $600 \mathrm{ks}$. Figure 11 shows changes of X-ray diffraction profiles on $773 \mathrm{~K}$ aging. Reflections of $\beta$ phase appeared at $1.2 \mathrm{ks}$ and isothermal $\omega$ phase was first identified at $3.0 \mathrm{ks}$.

The aging times at which $\beta$ reflections were first identified on $723 \mathrm{~K}$ and $773 \mathrm{~K}$ aging, i.e. $0.6 \mathrm{ks}$ and $1.2 \mathrm{ks}$, respectively, were longer than that on $673 \mathrm{~K}$ aging. Aging time at which reflections of isothermal $\omega$ phase were identified became shorter in order of $673 \mathrm{~K}$ and $723 \mathrm{~K}$. However, aging time at which isothermal $\omega$ phase was detected by XRD on $773 \mathrm{~K}$ aging was longer than that on $723 \mathrm{~K}$ aging. It is considered that the volume fraction of isothermal $\omega$ phase in specimen aged at $773 \mathrm{~K}$ was much lower than that of specimen aged at $723 \mathrm{~K}$ and $\alpha$ precipitation was accelerated by $773 \mathrm{~K}$ aging.

Figure 12 shows isothermal transformation diagram of Ti50Ta alloy expected from results of XRD and resistivity measurements. Plots indicate aging time at which $\beta$ or isothermal $\omega$ phase was identified by XRD. The nose of transformation of $\alpha^{\prime \prime}$ into $\beta$ was located at around $673 \mathrm{~K}$ and that for isothermal $\omega$ precipitate is around $723 \mathrm{~K}$. From this diagram, it is revealed that the reverse transformation of $\alpha^{\prime \prime}$ into $\beta$ occurred by aging above a temperature between $623 \mathrm{~K}$ and $673 \mathrm{~K}$ in Ti-50 mass\% Ta alloy.

\section{Conclusions}

Phase constitution and aging behavior in STQed Ti-Ta alloys were investigated through electrical resistivity, Vickers hardness measurements, X-ray diffraction and optical microscopic observation. Obtained results are as follows.

In the solution treated and quenched state, only reflections of hexagonal martensite, $\alpha^{\prime}$, were observed by XRD at room temperature in Ti-5Ta to 30Ta alloys, while only orthorhombic martensite, $\alpha^{\prime \prime}$, was identified by XRD at room temperature in Ti-40Ta and 50Ta alloy. Resistivity at RT and LN and $\mathrm{HV}$ increased with increase in Ta content. However, negative temperature dependence of resistivity was not apparent in all STQed alloys.

In Ti-5Ta to 20Ta alloys, no changes in resistivity and HV with isochronal treatment were observed. In 30Ta alloy, decrease of resistivity and increase of $\mathrm{HV}$ due to decomposition of $\alpha^{\prime}$ into $\alpha$ and $\beta$ were observed. In 40Ta alloy, decrease of resistivity and increase of $\mathrm{HV}$ due to decomposition of $\alpha^{\prime \prime}$ into $\alpha$ and $\beta$ were observed. In 50Ta alloys, significant increases of resistivity and resistivity ratio at $\mathrm{LN}$ due to reverse transformation of $\alpha^{\prime \prime}$ into $\beta$ appeared by isochronal treatment. It is considered that the starting temperature for reverse transformation of $\alpha^{\prime \prime}$ into $\beta$ is located at a temperature between $623 \mathrm{~K}$ and $673 \mathrm{~K}$.

From results of resistivity, HV and XRD profile changed by isothermal aging in Ti-50Ta alloy, the aging time for which transformation of $\alpha^{\prime \prime}$ into $\beta$ was observed on $673 \mathrm{~K}$ aging was shorter than at other aging temperatures. Isothermal $\omega$ phase was detected in specimen aged at $673 \mathrm{~K}, 723 \mathrm{~K}$ and $773 \mathrm{~K}$ by XRD.

\section{Acknowledgments}

One of authors, M. IKEDA, specially thanks to Professor Harvey M. Flower of Imperial College for his useful advice and comments.

\section{REFERENCES}

1) Hukushiyougu.seihinkaihatsu no shin-tenkai, ed. by Tore Research center, (Tore research center, Ltd., Tokyo, 2000) pp. 5-8.

2) H. Kawahara and M. Nakamura: Seitaikei kara mita zairyou-soshiki kaimen no syo seishitsu, Iyou zairyou no kagaku, ed. by Nihon kagakukai, (Gakkai syuppan senta, Tokyo, 1978) pp. 13-34.

3) M. Niinomi: Metall, Mater. Trans. A 33A (2002) 477-486.

4) T. Ahmed, M. Long, J. Silvetri, C. Ruiz and H. J. Rack: Titanium '95: Science and Technology, ed. by P. A. Blenkinsop, W. J. Evans and H. M. Flower (The Institute of Materials, London, 1996) pp. 1760-1767.

5) A. K. Mishra, J. A. Davidson, P. Kovacs and R. A. Poggie: $T i-13 N b-$ 13Zr: A New Low Modulus, High Strength, Corrosion Resistance Near-Beta Alloy for Orthopedic Implants, Beta Titanium Alloys in the 1990 's, ed. by D. Eylon, R. R. Boyer and D. A. Koss (TMS, Warrendale, 1993) pp. 61-72.

6) K. Wang, L. Gustavson and J. Dumbleton: The Characterization of Ti12Mo-6Zr-2Fe A New Biocompatible Titanium Alloy Developed for Surgical Implant, Beta Titanium Alloys in the 1990's, ed. by D. Eylon, R. R. Boyer and D. A. Koss (TMS, Warrendale, 1993) pp. 49-60.

7) E. W. Collings: A Sourcebook of Titanium Alloy Superconductivity, (Plenum Press, New York, 1983) pp. 213-298.

8) C. Baker: Metal Science Journal 5 (1971) 92-100. 
9) S. Kobayashi, K. Nakai and Y. Ohmori: Abstracts of 128th Spring Meeting of The Japan Inst. of Metals (2001) pp. 130.

10) T. Yashiki and F. Kamikubo: Corrosion Resistant Titanium Alloy and Surface Treatments for Titanium, "R\&D" Kobe Steel Engineering Reports 49 (1999) 43-48.

11) R. W. Margevicius and J. D. Cotton: Metall. Mater. Trans. A 29A (1998) 139-147.

12) E. A. Trillo, H. M. Obispo, S. W. Stafford and L. E. Murr: Electrochemical and Microstructural Analysis of Titanium-Tantalum Alloys for Metallic Implant Consideration, Non-Aerospace Applications of Titanium, ed. by F. H. Froes, P. G. Allen and M. Niinomi (TMS, Warrendale, 1998) pp. 201-206.

13) K. A. Bywater and J. W. Christian: Philos. Mag. 25 (1972) 1249-1274.
14) Iu A. Bagariatskii, G. I. Nosova and T. V. Tagunova: Sov. Phys. Dokl. 3 (1959) 1014-1018.

15) K. A. Bywater and J. W. Christian: Philos. Mag. 25 (1972) 1275-1289.

16) M. Ikeda, S. Komatsu, T. Sugimoto and K. Kamei: J. Japan Inst. Metals 53 (1989) 664-671.

17) R. Davis, H. M. Flower and D. R. F. West: Acta Metall. 27 (1979) 10411052.

18) H. M. Flower, R. Davis and D. R. F. West: Titanium and Titanium Alloys: Scientific and Technological Aspects, ed. by J. C. Williams and A. F. Belov (Plenum Press, New York, 1982) pp. 1703-1715.

19) M. Ikeda, S. Komatsu, T. Sugimoto and K. Kamei: J. Japan Inst. Metals 54 (1990) 743-751. 